\title{
Os impactos da pandemia de COVID 19 no Sistema de Justiça - algumas reflexões e hipóteses
}

\author{
The impacts of the COVID 19 pandemic on the Justice System - \\ some reflections and hypotheses
}

\author{
Marcelo Pereira de Almeida ${ }^{l}$ \\ Adriano Moura da Fonseca Pinto ${ }^{2}$
}

\begin{abstract}
RESUMO
A pandemia gerada pela circulação do Coronavírus tem gerado consequências graves em todo o mundo e os impactos nos sistemas jurídicos são imediatos e inevitáveis, afetando, por conseguinte, os espaços de solução de conflitos, sobretudo, o desenvolvido no âmbito jurisdicional. Dentro desta perspectiva, o presente texto visa trazer ao debate algumas reflexões sobre os principais impactos gerados por tal fenômeno no Sistema de Justiça Brasileiro e apresentar algumas hipóteses. ${ }^{3}$
\end{abstract}

\section{PALAVRAS-CHAVE:}

Coronavírus; Atividade Judiciária; Consequências.

\begin{abstract}
The pandemic generated by the circulation of the Coronavirus has brought serious consequences worldwide and the impacts on the legal systems are immediate and inevitable, consequently affecting the spaces for resolving conflicts, especially the one developed within the jurisdiction. Within this perspective, this text aims to bring to the debate some reflections
\end{abstract}

\footnotetext{
${ }^{1}$ Pós- Doutor em Direito Processual pela UERJ. Pós- Doutorando em Direito pela Universidade de Burgos (Espanha). Doutor em Ciências Jurídicas e Sociais pela UFF. Professor Adjunto de Direito Processual da UFF, Professor de Direito Processual Civil da Escola da Magistratura do Estado do Rio de Janeiro. Professor Permanente do PPGD (mestrado) da UCP. Coordenador da Pós- graduação em Direito Civil e Processual Civil do Unilasalle/RJ; Coordenador adjunto do Curso de Direito do Unilasalle/RJ; Professor de Teoria Geral do Processo e Direito Processual do Unilasalle/RJ. Membro do Instituto Brasileiro de Direito Processual Civil (IBDP), da Associação Brasileira de Direito Processual (ABDPro) e do Instituto Carioca de Processo Civil - ICPC. Advogado. 2 Coordenador Adjunto do Programa de Pós-Graduação em Direito (PPGD) da Universidade Estácio de Sá. Professor dos Cursos de Graduação e Pós-Graduação em Direito da Universidade Estácio de Sá. Gestor Nacional dos Cursos de Pós-Graduação Lato Sensu em Direito da Estácio. Membro do Comitê Científico da Conferência Universitária para el Estudo de La Mediación y el Conflicto - CUEMYC. Consultor Internacional de la FACPYA - Universidad Autônoma de Nuevo Leon (Monterrey, México). Doutor em Direito pela Universidad de BurgosEspanha. Especialista em História do Direito, Direito Civil e Processual Civil pela Universidade Estácio de Sá. Advogado. Bacharel em Ciências Jurídicas pela Universidade Cândido Mendes. Coordenador e autor de obras jurídicas. Editor do periódico Dissertar, da Revista da Graduação em Direito da Estácio e da Revista de PósGraduação Lato Sensu em Direito da Estácio. Voluntário e membro do Conselho Fiscal da Casa Ronald McDonald-RJ. Membro da Law and Society Association - LSA (Washington, DC - USA). Membro dos Observatórios de Política Pública, Direito e Proteção Social e Mediação. Membro da Comissão de Estudos em Processo Ciivl da OAB-RJ.

${ }^{3} \mathrm{O}$ texto teve a colaboração da pesquisadora Letícia Pereira de Araujo. Advogada. Graduada em direito pelo centro universitário La Salle de Niterói - Lattes: http://lattes.cnpq.br/8231532195654026
} 
on the main impacts generated by this phenomenon in the Brazilian Justice System and to present some hypotheses.

\section{KEYWORDS:}

Coronavirus; Judicial Activity; Consequences.

\section{NOTAS INTRODUTÓRIAS}

Este ensaio visa trazer ao debate algumas reflexões sobre os principais impactos gerados pela crise oriunda da Pandemia da COVID-19 no Sistema de Justiça Brasileiro e apresentar algumas hipóteses.

No intuito de observar as consequências oriundas desta Pandemia suportadas pelo Sistema Judiciário, faz-se necessária uma breve demonstração do cenário temporal do Coronavírus para compreender a sua evolução no âmbito nacional.

Em meados de dezembro de 2019 foram constatados e reportados à Organização Mundial da Saúde (OMS) casos de pneumonia em Wuhan, China.

Em 07 de janeiro de 2020 o vírus 2019-nCoV, foi identificado pela referida Organização como o agente responsável das infecções na China que ocasionam diversas enfermidades, mais brandas e mais graves.

A OMS decretou surto de Coronavírus como Emergência de Saúde Pública de Importância Internacional em 30 de janeiro de 2020 e sua infecção já era considerada uma epidemia.

Somente em 03 de fevereiro de 2020, o Brasil declara o Coronavírus como Emergência de Saúde Pública de Importância Nacional através da Portaria do Ministério da Saúde no 188/2020, levando em consideração que os agentes infecciosos representam uma doença de gravidade elevada e extrapolam a capacidade do Sistema Único de Saúde.

Como consequência, o Brasil promulgou em 06 de fevereiro de 2020 a Lei n $^{\text {o }}$ 13.979/2020, dispondo acerca das medidas de enfretamento a serem tomadas e logo após, em 
11 de fevereiro de 2020, a OMS identifica os sinais e sintomas das doenças causadas pelo COVID-19.

O Ministério da Saúde publicou Plano de Contingência Nacional para Infecção Humana pelo Coronavírus em 13 de fevereiro de 2020, o qual sofre atualização periódica a fim de corresponder o desenvolvimento das medidas a serem adotadas.

Em 11 de Março de 2020 a OMS declara a COVID-19 como pandemia, pois a disseminação da doença atinge um nível global cruzando as fronteiras internacionais.

O Brasil publicou a Portaria $n^{\circ} 356 / 2020$, promovendo medidas de isolamento para evitar a propagação da infecção e transmissão local para garantir a manutenção dos serviços de saúde.

A partir da primeira confirmação da infecção de COVID-19 no Brasil, Estados como o Rio de Janeiro e São Paulo publicaram decretos de $n^{\circ}$ 64.862/2020 e $n^{\circ} 46.970 / 2020$ a respeito das medidas temporárias e emergenciais a serem tomadas como prevenção de contágio.

Em 16 de março de 2020 foi decretado Estado de Emergência Pública, ou seja, aquela situação anormal provocada por desastres que causam danos e comprometem a capacidade de resposta do Poder Público, nos Estados de São Paulo e Rio de Janeiro, através dos decretos no $59.283 / 2020$ e no 46.973/2020.

Após essa dinâmica, Estados de São Paulo e Rio de Janeiro publicam decretos ( $n^{\circ} 64.879$ e no 46.984) reconhecendo o Estado de Calamidade Pública.

Em decorrência de tais fatos, vários tribunais do país editaram atos normativos determinando a suspensão dos prazos por períodos variados e, em seguida, o Conselho Nacional de Justiça aprovou a Resolução no 313 em 19 de março, determinando a suspensão dos prazos processuais em todos os seguimentos do Poder Judiciário do país até 30 de abril de 2020, exceto para o STF e a Justiça Eleitoral e ainda, instituiu o Plantão Extraordinário com a suspensão dos trabalhos presenciais dos Tribunais, determinando a realização remota. 
Os efeitos desses atos de suspensão, sobretudo, da Resolução $n^{\circ} 313$, que uniformiza as regras e o período de sobrestamento, são dos mais variados, na medida em que são suspensos os prazos, mas não necessariamente o trâmite processual.

Diante deste quadro algumas questões são postas para tentar amenizar os impactos dessa paralização processual que muitas vezes pode ser aparente.

Para alcançar o objetivo proposto, o texto é dividido em cinco seções e algumas subseções, conforme destacado no sumário.

Empregou-se para tanto o método dedutivo, com análise documental e se alcançou algumas hipóteses possíveis que podem diminuir as nefastas consequências da paralização da atividade jurisdicional num momento em que as pretensões aumentam exponencialmente.

\section{CONSEQUENCIAS DA SUSPENSÃO DOS PRAZOS PROCESSUAIS}

Antes de iniciar as considerações a respeito da suspensão dos prazos processuais é importante a observação de algumas conceituações para a compreensão acerca do tema.

Partimos da premissa que o processo se configura como uma instituição de garantias (COSTA, 2019), mas se materializa pelo procedimento em contraditório (FAZZALARI, 1958) que se desenvolve por uma sucessão organizada de atos independentes, destinados na maioria dos casos, à solução de um litígio, com vinculação do magistrado e das partes a uma pluralidade de deveres e direitos.

Com o seu início e devido prosseguimento, há um termo final, que em regra, ocorre pela sentença, preferencialmente de mérito, conforme as orientações trazidas pelo CPC/2015 em algumas passagens, na qual podem ser citados os artigos $3^{\circ}, 6^{\circ}, 488$, entre outros.

Em seu desenvolvimento, ocorrem situações e incidentes que podem gerar crises que conduzem paralização no trâmite processual e, que por conseguinte, levam a suspensão ou interrupção de prazos processuais. 
Desta forma, diante da situação da pandemia do Covid-19 e a publicação da Resolução no 313/2020, há o questionamento se ocorrerá a suspensão dos prazos processuais ou a própria suspensão do processo e quais são as suas possíveis consequências.

Neste sentido, o art. 313 do CPC prevê as principais hipóteses de suspensão do processo e dentre as causas previstas legalmente, encontra-se no inciso VI do referido artigo, a previsão da suspensão do processo por motivo de força maior, no qual até perdurar o evento, o processo fica paralisado, sem que haja qualquer pratica processual, exceto nas hipóteses de atos urgentes, nos moldes do Art. 314 do CPC. Valendo destacar que essa hipótese conduz em regra a suspensão dos prazos processuais, mas em relação aos prazos processuais para interposição de recursos que já estavam fluindo ao tempo da suspensão, a consequência é a interrupção do prazo, conforme dispõe o artigo 1.004 do CPC/2015, o que significa dizer que, ao fim da paralização, o prazo será restituído na integralidade para o eventual recorrente.

É importante frisar neste contexto, que a Resolução $n^{\circ} 313$ do CNJ determinou a suspensão dos prazos processuais, fato que não ocasiona a paralização do processo invariavelmente, mas, dependendo do momento em que o processo se encontre, essa suspensão poderá ser inevitável, como por exemplo, se estiver na fase de apresentação de resposta do réu e este não a apresente voluntariamente, não haverá, neste caso, possibilidade de avanço.

Observa-se, assim, que a suspensão dos prazos processuais impostos pela Resolução 313 do $\mathrm{CNJ}$, não impede o prosseguimento do processo, entretanto, verifica-se que com a realização do trabalho remoto por parte dos magistrados, servidores e serventuários, somente indica a possibilidade de prosseguimento ao andamento processual de forma virtual, a qual sofre com a oscilação da conexão da internet e disponibilidade de um número maior de servidores capazes de atender a demanda por meio de aparelho telefônico ou acesso aos endereços eletrônicos, além de, em vários casos, depender de atos voluntários de partes para pratica de atos referentes aos seus ônus processuais, renunciando a suspensão do prazo, conforme o exemplo dado em relação ao momento de defesa do réu. Tudo isso é excepcionado nos casos de urgência que exigem a provocação do plantão judiciário, como tem se desenhado nesse momento de crise como os pleitos destinados a efetivação de políticas públicas referentes a saúde e assistência social. 
Macroproblema posto, com seus diversos reflexos, passa-se a seguir a análise de questões pontuais com as hipóteses e inferências levantadas.

\section{HIPÓTESES PARA PERMITIR A OBSERVÂNCIA DO PRINCÍPIO DA CONTINUIDADE DA PRESTAÇÃO JURISDICIONAL}

A EC nº 45 de 2004, responsável pela macro "Reforma do Poder Judiciário", consolidou o que se convencionou denominar de princípio da continuidade da prestação jurisdicional no artigo 93, XII, dispondo que nos dias sem expediente forense, haverá funcionamento e atendimento permanente em regime de plantão.

Apesar da expressa previsão constitucional, essa leitura já poderia ser extraída do ordenamento jurídico pátrio com o emprego de um dos métodos de integração do direito previstos no Art. 4 da LINDB. O princípio permite a correta interpretação do sistema jurídico e a sua observância é um dos pilares de todo o Direito.

Desta forma, o Princípio da continuidade da Prestação Jurisdicional, poderia ser extraído do artigo $6^{\circ}$, $\$ 1$ da Lei $n^{\circ} 8.987 / 95$, que dispõe que a prestação do serviço público deve ser ininterrupta a fim de satisfazer o dever do Estado em promover os direitos fundamentais.

Nesse sentido, indaga-se como seria possível promover e satisfazer os direitos de cada cidadão em uma situação de crise sem precedentes, gerada por uma Pandemia com a suspensão dos prazos processuais, audiências e o atendimento a serventia cartorária.

No intuito de se permitir a observância do princípio em tela, passa-se a apontar alguns vetores possíveis para se alcançar a tutela jurisdicional efetiva nesse momento de necessidades prementes. 


\subsection{Negócios jurídicos processuais e calendarização processual}

Dentre as hipóteses levantadas que podem permitir a continuidade da prestação jurisdicional indicam-se primeiramente os negócios jurídicos processuais e a calendarização processual, tendo em vista o Art. 190 do CPC instituir uma cláusula geral de negociação sobre o processo.

O negócio jurídico processual provém do negócio jurídico, aquela manifestação de vontade consciente, existente, com limites pré-determinados e estruturados, associado ao ato processual, ou seja, norma jurídica referente a algum procedimento.

Neste sentido, os negócios jurídicos processuais permitem a realização de acordos em relação ao procedimento, desde que o litígio verse sobre direitos que admitem transação e as partes apresentem plena capacidade.

Essa disposição legal, representa uma novidade no ordenamento processual brasileiro de cariz tradicionalmente publicista e permite negócios entre as partes sobre direitos, deveres e ônus processuais, o que poderia permitir a tramitação do processo com prazos suspensos pela renúncia negociada da suspensão dos prazos, como o de resposta, o de réplica, de especificação de provas e de apresentação de recursos etc.

Há, da mesma forma, a possibilidade convencional de se estabelecer um calendário para a realização da prática de atos processuais, nos moldes do Art. 191 do CPC.

Em relações conflituosas, que envolvem animosidades entre as partes, as convenções processuais, podem parecer algo utópico, mas, conflitos entre empresas que a arbitragem representa uma realidade distante pelo alto custo, pode representar um caminho bem viável, além da viabilidade nos conflitos referentes aos direitos coletivos em sentido amplo.

Desta forma, a responsabilidade na condução dos processos também pode ser dividida com as partes, as quais são capazes de delimitar ou criar datas para a realização de atos processuais, como data de audiência e suspensão do processo a fim de alcançar o objeto da demanda judicial, qual seja, resolução do conflito. 
Consequentemente, a realização da calendarização do processo não prejudica o sistema de justiça, mas sim, permite a continuidade da prestação jurisdicional, atendendo os interesses das partes ao promover a satisfação e defesa dos direitos fundamentais.

\subsection{A Importância dos Métodos Consensuais de Solução de Conflitos}

Acompanhando o movimento democrático por intermédio da participação de um terceiro nas atividades conciliatórias, os métodos consensuais de soluções de conflitos promovem a possibilidade de uma maior atuação das próprias pessoas envolvidas na controvérsia.

A mediação que, em apertada síntese, permite a um terceiro realizar a aproximação das partes para que elas viabilizem um acordo, e a conciliação, feita por um ator que pode propor soluções, são espécies de autocomposição de conflitos que aproximam as partes e fornecem um empoderamento dos cidadãos como atores na solução de seus conflitos, além da negociação direta e de outros métodos capazes de promover soluções adequadas e eficientes para os mais variados conflitos. Estes mecanismos formam, portanto, o binômio da liberdade-autoridade no comportamento das partes acrescida da viabilidade dos negócios jurídicos processuais, como debatido anteriormente, por fornecer uma flexibilidade para a definição da controvérsia mesmo em casos de judicialização.

Como fator potencializador da lógica do consenso (ALMEIDA; FILPO, 2018) em momentos de distanciamento social como o que está sendo experimentado neste momento de acentuada de crise gerada pela Pandemia, vem sendo difundido os ODRs (Online Dispute Resolution), plataformas de fácil manuseio que permitem a solução de controvérsias de modo prático e eficiente em curto espaço de tempo. Pode ser citado como exemplo, o espaço criado pelo Ministério da Justiça para solucionar conflitos consumeristas.

Infere-se, pois, que os métodos consensuais de solução de conflito são instrumentos de ação social participativa importantes para o acesso à justiça e contribuem para a eficácia e agilidade da administração dos conflitos, dentro e fora do Poder Judiciário e, neste momento de crise podem trazer resultados satisfatórios para a efetivação de direitos. 


\subsection{A tutela provisória de urgência}

A tutela provisória, sobretudo, a tutela provisória de urgência, se apresenta como hipótese de imediata efetivação de diretos (LEMOS, 2017) e, em momentos de crise, com demandas prementes, se mostra como via muito salutar que se potencializa na medida em que, a própria Resolução 313 do CNJ destaca a sua manutenção.

Este mecanismo, previsto no Art. 300 do CPC, é compreendido na necessidade de comprovação da probabilidade do direito e do perigo de dano irreparável ou de difícil reparação.

Tendo em vista que não existem hipóteses taxativas, deve-se fazer um enquadramento de cada situação para a concessão de cada pedido.

A tutela provisória de urgência se subdivide em duas espécies, podendo ser o pedido de caráter cautelar ou antecipado.

No pedido cautelar, a parte pretende resguardar um direito preexistente ao assegurar a efetividade do mérito (LEMOS, 2017), enquanto o pedido antecipado busca realizar o direito perseguido na sentença. São métodos criados e aperfeiçoados especificamente para modular os efeitos nefastos do tempo no processo.

Ambas podem ser requeridas na petição inicial, como um momento incidental ou ainda, em caráter antecedente a ser requerida antes da apresentação da petição inicial do pleito, considerado principal.

Em decorrência da atual situação excepcionalíssima causada pela Pandemia do coronavirus, é justificável e necessária a manutenção da atividade judiciária nos casos que buscam a concessão de tutela provisória de urgência.

Nesse sentido, a Resolução 313 foi precisa ao dispor que a suspensão dos prazos processuais não impede a prática de atos necessários à preservação de direitos de natureza urgente. 


\section{O PROBLEMA DAS AUDIÊNCIAS E PLENÁRIOS VIRTUAIS}

Com as inovações tecnológicas as diversas áreas de conhecimento foram impactadas intensamente, não seria diferente no cenário jurídico e, por conseguinte o de efetivação de direitos.

O processo eletrônico e os ambientes virtuais para a prática de atos processuais (NEVES, 2017) não são mais realidades distantes, mas sim, no caso brasileiro, considerados os espaços principais para o exercício da atividade jurisdicional.

Diante desse quadro, que se transforma velozmente, as práticas vêm sendo adaptadas, os profissionais que atuam no sistema de justiça, precisaram e precisam constantemente de atualização e formação, para conseguirem transitar bem nesses espaços.

Nesses cenários, alguns ambientes promovem atos que conseguem diminuir as distâncias dos espaços físicos dos prédios dos fóruns e tribunais, como as audiências por vídeo conferência e os plenários virtuais.

Para compreender melhor o problema das audiências e plenários virtuais, se fará um breve apontamento das suas desvantagens, entre elas, a incomunicabilidade entre os sistemas e o obstáculo ao acesso ao Poder Judiciário aos excluídos digitalmente e a interferência negativa na comunicação dos sujeitos processuais.

Como a universalização do acesso à internet está distante de ser realizado, uma vez ser concentrado o seu acesso às camadas economicamente mais favorecidas, cria-se um distanciamento do acesso ao Poder Judiciário.

Ainda, a comunicabilidade pode ser afetada ao passo que a rede rompe a utilização dos sentidos ao trocá-los por frases cruzadas pelo computador.

Porém, nesse momento de crise gerada pela Pandemia, com o isolamento social utilizado como a principal política pública de combate a disseminação do vírus, haja vista a ausência de vacina e de terapia capaz de controlar eficazmente a doença, as audiências por vídeo 
conferência podem representar uma ferramenta muito promissora para que a atividade jurisdicional não seja mitigada.

Já o denominado plenário virtual consiste unicamente na votação digital dos magistrados referente às matérias submetidas, ou seja, há uma supressão das sessões deliberativas eliminando os debates profundos e necessários para a construção adequada da decisão judicial no âmbito dos tribunais.

O CPC/2015, permite esse formato de sessão no artigo 945 para os julgamentos de qualquer recurso ou ação de competência originária que não admitem sustentação oral e, mesmo assim, os representantes processuais das partes podem impugnar a utilização da sessão virtual, sem sequer motivar, o que seria suficiente para obstar o procedimento dessa forma (artigo 945, $\S \S 1^{\circ}$ e $2^{\circ}$ do CPC).

Ao dispensar a realização das sessões presenciais, há um afastamento dos próprios julgadores uns aos outros, comprometendo o caráter deliberativo da atividade judicante, criando uma monocratização das decisões, pois as suas deliberações não podem ser resumidas a soma dos votos de cada julgador.

Consequentemente, as inovações tecnológicas, em especial as audiências e plenários virtuais, em tempos de normalidade, podem desconfigurar a democracia das decisões por comprometer a comunicação dos sujeitos processuais ao substitui-los por método quantitativo representado pela somatória dos votos, mas em tempos de crise, com o aperfeiçoamento e releitura dos sistemas, tem o potencial de permitir a continuidade da prestação jurisdicional com qualidade, conforme se passa a apontar na seção seguinte.

\subsection{Vídeo conferência como possibilidade viável}

Diante da suspensão dos prazos processuais e cancelamento das audiências, passa-se a expor hipóteses viáveis para a continuidade da prestação jurisdicional, com a realização de audiências e um redesenho dos plenários virtuais. 
A realização de audiências por vídeo conferência representa um instrumento de celeridade e desburocratização da Justiça embora não seja uma presença física, ela busca reproduzir com máxima fidelidade uma audiência real (GOMES, 2012).

Amparando a sua aplicação, estão os princípios da eficiência, celeridade, economicidade e segurança pública.

No mais, a realização de audiência por vídeo conferência em tempo real permite que as partes se manifestem livremente com todas as suas expressões expostas a serem ouvidas e vistas pelo julgador por meio de câmeras e microfones.

Desta forma, a vídeo conferência é um recurso tecnológico que possibilita a manutenção do serviço à sociedade e do bem público em tempos de difíceis, como o vivido atualmente, por atender a finalidade constitucional da ampla defesa e acesso ao Poder Judiciário.

Da mesma forma, se mostra perfeitamente viável a utilização da vídeo conferência nos plenários virtuais, com uma releitura do artigo 945 e seus parágrafos do CPC/2015, para permitir que os processos pendentes de julgamento, neste período de suspensão dos prazos e dos acessos físicos, tenham o seu trâmite retomado, permitindo-se a sustentação oral por esse método. A falta de regulação não pode servir de impeditivo para a observância do princípio da continuidade da prestação jurisdicional, corolário da cláusula do devido processo. Basta que os tribunais, utilizando-se da teoria dos poderes implícitos (ALMEIDA, 2014), por meio de resoluções, criem essa dinâmica e implementem, o mais rápido possível a metodologia, de sorte a viabilizar a tutela jurisdicional adequada.

Para a implementação desse espaço virtual, será necessário investimento e preparação de pessoal em curto espaço de tempo, de sorte a permitir que os ambientes virtuais ganhem espaço para a efetivação da prestação jurisdicional, não só para a busca de soluções consensuais, em sessões de conciliação ou mediação, mas também para se realizar a instrução do processo, com oitivas de partes, testemunhas e eventuais técnicos, além da criação dos espaços para a sustentação oral por vídeo conferência nas sessões de julgamento dos tribunais. 


\section{ALGUMAS INFERÊNCIAS}

Diante das reflexões feitas no presente ensaio, permitiu-se inferir que com a pandemia provocada pelo Coronavírus e após o reconhecimento de calamidade pública, a Resolução 313 do Conselho Nacional de Justiça impôs, de forma transitória, a suspensão dos prazos processuais e o trabalho presencial de magistrados, servidores e outros colaboradores nas unidades judiciárias, exceto para o STF e Justiça Eleitoral, mas não a suspensão dos processos, que passaram a tramitar de forma mitigada neste período.

A regra geral é de que os atendimentos não sejam presenciais, motivo pelo qual cada unidade judiciária deverá manter um canal de atendimento remoto e somente na impossibilidade desse atendimento e em casos urgentes é possível realizá-los de forma presencial durante o expediente de plantão forense regulado por cada tribunal.

Em contrapartida, as consequências dessa situação trazem o questionamento, com base no princípio da continuidade da prestação jurisdicional, acerca das possibilidades em permitir a manutenção do sistema de justiça nas hipóteses de negócios jurídicos processuais, casos urgentes e a utilização do vídeo conferência como uma ferramenta capaz e eficaz de ser utilizada.

Neste sentido, permite-se verificar que os sujeitos processuais podem fixar um calendário para a prática de atos processuais, e ainda, podem se valer dos métodos consensuais de solução de conflitos dentro e fora do Poder Judiciário, inclusive se valendo dos ODRs, que ganham cada vez mais espaço no cenário brasileiro.

Destacou-se, ainda, que nos casos que envolvam a concessão da tutela provisória de urgência necessitam da manutenção da atividade judiciária para que consiga alcançar os objetivos prementes.

Outro importante ponto é a viabilidade de continuar as audiências de forma virtual e em tempo real através do vídeo conferência, o qual permite e atende a ampla defesa e o acesso ao Poder Judiciário, além da possibilidade de utilização dessa metodologia para a realização de 
sustentação oral nos plenários virtuais, que nesse períodos de crise, pode ter sua regulação relida.

Destarte, as medidas tomadas pelo Poder Público em combate ao Coronavírus são necessárias, por outro lado, não basta somente suspender as suas atividades, elas devem ocorrer de forma segura com o devido auxílio de sistemas remotos, como proposto acima, para que não cause um dano ainda maior ao suprimir o acesso e manutenção da justiça.

Essas são apenas algumas reflexões que podem contribuir para que a prestação jurisdicional tenha continuidade de modo satisfatório, num momento em que as preensões aumentam e, nessa medida, a satisfação das pretensões não podem se distanciar, de sorte a não gerar o agravamento da crise.

\section{REFERÊNCIAS}

ALMEIDA, Marcelo Pereira de. Precedentes Judiciais - Análise crítica dos métodos empregados no Brasil para a solução de demandas de massa. Curitiba: Juruá Editora, 2014. v. 1.

A jurisdição na perspectiva publicista e privatista no contexto da solução de demandas individuais de massa - Notas sobre o incidente de resolução e demandas repetitivas previsto no PLS166/10. Revista eletrônica de direito processual, v. 7, p. 158-175, 2011.

; FILPO, Klever Paulo Leal. Ações contenciosas de família na Lei no 13.105/2015: lógica do consenso x lógica do contraditório. V. 25. Série 98. Revista Brasileira de Direito Processual. 2018.

COSTA, Eduardo da Fonseca de. Instituição de Poder e Instituição de Garantia. Coluna Garantismo Processual. Empório do Direito. 2020. Disponível em: <https://www.flickr.com/photos/underpants/12069086054>. Acesso: 07 de mar. 2020.

CUNHA, Leonardo Carneiro da. O princípio do contraditório e a cooperação no processo. Revista Brasileira de Direito Processual (Impresso), v. 79, p. 147-159, 2012.

DIDIER JR, Fredie. Princípio da Cooperação. In: Normas Fundamentais. FREIRE, Alexandre; DIDIER JR, Fredie; NUNES, Dierle. Salvador: Juspodium. 2016. 
FAZZALARI, Elio. Diffusione del processo e compiti della dottrina. Rivista Trimestrlle di Diritto e procedura Civile. n. 3. 1958.

GOMES, Rodrigo Carneiro. A lei 11.900/2009 e a adoção da videoconferência no brasil. Revista dos tribunais, v. 3, p. $1209-1230,2012$.

GOUVEIA, Lúcio Grassi de. Cognição processual cível: atividade dialética e cooperação intersubjetiva na busca da verdade real. Revista dialética de Direito Processual. São Paulo: Dialética. 2003.

LEMOS, Vinicius Silva. A necessidade de separação da tutela provisória antecipada antecedente em duas espécies diferentes. Revista de Processo, v. 266/2017, p. 255-287, 2017.

MITIDIERO, D. F. . Colaboração no Processo Civil - Pressupostos Sociais, Lógicos e Éticos, 3. ed.. 3. ed. São Paulo: Revista dos Tribunais, 2015. v. 1. 204p.

MULATI, Natalia Queiróz. Causas de suspensão do processo civil e o novo código de processo civil. Revista dos Tribunais. v. 963/2016, p. 263-289 2016.

NEVES, Aline Regina das. Processo e tecnologia: do processo eletrônico ao Plenário Virtual. Revista dos Tribunais. v. 986/2007, p. 87-110, 2017.

NUNES, Dierle José Coelho. Processo Jurisdicional democrático: uma análise crítica das reformas processuais. 1. ed. Curitiba: Juruá Editora, 2008. v. 1. 286p.

SILVA, Paula Costa e. Acto e processo: O dogma da irrelevância da vontade na interpretação e nos vícios do acto postulativo. Coimbra: Coimbra. 2003.

SOUSA, Miguel Teixeira de. Estudos sobre o novo processo civil. 2 ed. Lisboa: Lex. 1997.

TAKAHASHI, Bruno. Entre a liberdade e a autoridade: os meios consensuais no novo código de processo civil. Revista dos Tribunais. v. 264/2007, p. 497-552, 2017.

Data de Submissão: 13/04/2020

Data de Aceite: 20/04/2020 